\title{
Suicide in Trans Populations: A Systematic Review of prevalence and correlates
}

\author{
Jay McNeil Lancaster \\ University, UK. \\ Sonja J. Ellis \\ Australian Catholic University. \\ Fiona J R Eccles \\ Lancaster University, UK.
}

\begin{abstract}
Author Note
Jay McNeil, Independent Researcher; Sonja J. Ellis, School of Psychology, Australian

Catholic University; Fiona J R Eccles, Division of Health Research, Lancaster University, UK.
\end{abstract}

This paper is based on the doctoral thesis of the first author, who graduated DClinPsy from Lancaster University, UK in 2016. The thesis was co-supervised by the second author (at the time based at Sheffield Hallam University, UK; and subsequently at the Australian Institute of Psychology/Australian Institute of Professional Counsellors, Brisbane, Australia) and the third author (based in the Division of Health Research at Lancaster University, UK).

Correspondence to be directed to Jay McNeil at Jay@ traverse-research.com

(C) 2017, American Psychological Association. This paper is not the copy of record and may not exactly replicate the final, authoritative version of the article. Please do not copy or cite without authors permission. The final article will be available, upon publication, via its DOI: 10.1037/sgd0000235 


\begin{abstract}
Trans people experience high rates of attempted suicide and suicidal ideation. No study to date has collated the various findings concerning correlates of trans-suicide. This systematic review aimed to summarise the available data and provide recommendations based on this evidence. Papers were included if published before February 2016, English, were peer reviewed, and presented data concerning trans people's suicide attempts or ideation. Nine databases were searched, and 30 papers were selected. Discrimination emerged as strongly related to suicidal ideation and attempts, while positive social interactions and timely access to interventions appeared protective. Limitations included differences in how papers defined trans people or measured suicide, and in their largely cross-sectional nature, making assumptions about causality in reference to lifetime ideation or attempts impossible. However, results clearly indicated a need to work at both individual and structural levels to reduce societal and service-level discrimination, enhance peer support, and ensure access to required interventions. The review highlights the need to explore suicidality in the trans population both in relation to general suicide models as well in relation to models of minority stress.
\end{abstract}

Keywords: transgender, suicidal ideation, suicide attempts, systematic review

\title{
Public Significance Statement
}

The findings presented here suggest that suicidality among trans people is complex; comprising a mix of individual, systemic and structural factors. This paper therefore highlights the importance of interpreting suicidal behaviour in relation to specific models of minority stress, and of working to address this issue across these different levels. 


\section{Suicide in Trans Populations: A Systematic Review of Prevalence and Correlates}

The term trans is used to refer to a diverse range of people whose personal experience of gender is different from the conventional construction of gender as associated with the sex they were assigned at birth. Many people may be included under the umbrella term trans, such as trans men (those assigned female at birth but who identify as primarily masculine or male), trans women (those assigned male at birth but who identify as primarily feminine or female), those who define their gender as non-binary (e.g. 'bigender', 'androgyne', 'polygender'), and those who do not define their gender at all (e.g. 'neutrois'). Trans people may have a fluid gender identity, and may use more than one identity label at a time (e.g. 'trans woman' and 'genderqueer') or a range of labels over time. While some trans people may undergo medical interventions (e.g. hormone therapy; gender confirmation surgery) in relation to their gender identity, others may not. Similarly, some may socially transition (i.e. change their name and/or gender presentation).

Research and anecdotal evidence would seem to suggest that trans (or gender-diverse) people are at particular risk of suicide. For example, one UK study, indicates that the lifetime prevalence of suicidal ideation may be as high as $84 \%$ (McNeil, Bailey, Ellis, Regan, \& Morton, 2012) with $48 \%$ of ideators having attempted suicide (Bailey, Ellis, \& McNeil, 2014). Similarly, del pozo de Bolger, Jones, Dunstan, \& Lykins (2014) report that within their sample $35 \%$ of trans people had attempted suicide in their lifetime. Rates are also reported to be high in studies measuring suicidal ideation and attempts over the preceding year (e.g. Bauer, Pyne, Francino, \& Hammond, 2013). Although there is a dearth of definitive data, rates of suicidal ideation and attempts in the trans population would appear to be substantially higher than the general population (e.g. 9.2\%, Nock et al., 2008, and 5\%, International Association for Suicide Prevention, 2012, respectively). These rates would also appear to be considerably higher than for other marginalised groups. For example, when 
compared to lesbian, gay and bisexual (LGB) people, trans people were reported to be "162\% more likely to have ever seriously considered committing suicide" (Irwin, Coleman, Fisher, \& Marasco, 2014 p. 1181).

In the general population, the rate of suicidal ideation and attempts is related to the rate of completed suicide. In reviewing risk factors for suicide, Mościcki, (2001) highlights how having a history of suicide attempt is a substantial risk factor for later completed suicide. However, rates of completed suicide are difficult to ascertain for the trans population. It would be highly unusual for a person's trans status to be recorded on a death certificate; it is therefore not possible to ascertain trans suicide rates from coronial data. Conversely, because the trans population is 'hard-to-reach' published studies tend to comprise limited, and typically self-selecting, samples making it difficult to assess the extent of suicidality in the trans population as a whole. For example, the majority of studies adopt a gender binary approach to trans people, sampling only trans men and/or trans women; thus excluding nonbinary trans people. In other cases, sample selection is restricted to highly specific subgroups of the trans population, such as 'trans women with a history of sex work' (e.g. Nemoto, Bodecker \& Iwamoto, 2011) or solely those undergoing surgical intervention (e.g. Heylens et al., 2014). Together these factors contribute to partial information and potential underreporting of suicide rates in trans populations (Bauer, Scheim, Pyne, Travers, \& Hammond, 2015; Haas et al., 2010).

The negative impact that prejudice and discrimination have on the mental health and wellbeing (including increased risk of suicide) of individuals from marginalised groups has been well established (e.g. see Friedman, 1999; Meyer, 2003). Given the structural dominance of gender in society, trans people have a heightened consciousness of the extent to which their bodies and physical presentation do or do not confirm to gender norms. While trans people are at significant risk of transphobic victimisation, recent studies have shown 
that they have a heightened perception of this risk (Ellis, Bailey \& McNeil, 2016) and go to great lengths to avoid being victimised (Ellis, McNeil \& Bailey, 2014). In addition to social stigma, there are a number of personal challenges that trans people need to negotiate which also have a negative bearing on mental health and wellbeing. Factors such as distress in relation to gender, fears about transitioning, and delays/refusals in accessing gender confirmation interventions all contribute negatively to trans people's wellbeing; and are viewed by many trans people as key factors in suicidality (e.g. see Bailey, Ellis \& McNeil, 2014). As highlighted by Clements-Nolle et al., (2006) in LGB populations a clear link has been established between gender non-conformity and suicidality. Given that gender (as opposed to sexuality) is directly at stake for trans people, it is reasonable to assume that this would play a central part in placing trans people at risk of suicide.

Meyer's (2003) Minority Stress Hypothesis (MSH) offers a more complex explanation for poor mental health in minority groups, which encompasses issues of social capital and microaggressions in its dividing of minority stressors in to proximal and distal factors. In relation to suicide, minority populations experience the same risk factors as majority group members (e.g. low income, not being married; Nock et al., 2008); however they are also subject to additional stressors specific to their minority experience, which has an additive negative effect on mental health. Testa, Habarth, Peta, Balsam and Bockting (2015) adapted the model for use with trans and gender nonconforming people. They highlighted that trans-specific distal (external) factors would include gender-related discrimination, rejection and victimisation, and non-affirmation of someone's gender identity. Proximal (or internal) factors might include internalised transphobia, negative expectations, or concealment. The authors finally highlighted resilience or protective factors, including community connectedness and pride. Thus the factors identified by Meyer (2003) have been easily adapted for trans populations. Although Meyer's Minority Stress Hypothesis has 
recently been criticised for not considering the institutionalised nature of stressors affecting LGBT individuals (e.g. see Riggs \& Treharne, 2016) it still provides a useful framework for understanding suicidality at an individual level; and is widely used in other studies.

Given the high rates of suicidal ideation and attempt among trans people, it is important to understand the factors contributing to this, and theories such as MSH offer a way of understanding how these factors may lead to such an outcome. Although research has explored trans people's suicidality, and a review exists which explores prevalence rates of suicidal ideation and attempt in these populations (Marshall et al., 2016), no systematic reviews have focussed on collating the current evidence concerning correlates of these. Despite limitations in the breadth of samples (i.e. the bias towards binary trans participants) over the past 15 years there has been a proliferation of survey-based studies interfacing with trans suicide. Therefore, now is an appropriate time to undertake a cross-study examination of the determinants of suicide in trans populations. This review aims to summarise the evidence concerning factors which correlate with suicidal ideation and attempt in trans populations. The review also aims to provide recommendations for enhancing the future evidence-base for supporting trans mental health.

\section{Method}

\section{Inclusion and Exclusion Criteria}

Studies included in this review comprised those employing quantitative data about factors relating to suicidal ideation and/or attempts in trans people; and which were published in English. Studies were excluded if they were qualitative or if they aggregated data about trans people with other populations (e.g. combining trans and LGB people's data).

\section{Search Strategy}


A literature search was conducted in November 2016 using a range of databases relevant to psychology and health sciences. These were AHMED, Academic Search Complete, CINAHL, PsycInfo, PsycArticles, Web of Science, Scopus, OVID-EMBASE and Pubmed.

The following search terms were used to refer to trans people, combined via the operator 'OR': gender dysphoria, transgender, transsexual, gender variant, non-binary, genderqueer, genderfluid, gender non-conformity, agender, two-spirit, kathoey, M2F, MTF, F2M, FTM, trans $\mathrm{m}^{*}$, trans $\mathrm{w}^{*}$, male to female, female to male, androgyne, bigender, gender neutral, neutrois, bissu, kinnar, khusra, gender identity disorder. The identity-related terms rather than diagnostic-related terms originated from different potential descriptions of trans people that were included in McNeil et al (2012). In that study, gender related options were determined by an advisory panel which included representation from different cultural trans communities, including researchers and clinicians with extensive theoretical and/or practical experience. Searches were conducted using free text terms rather than MeSH headings, as these headings did not return a sufficiently wide variety of the different terms that may be used to represent trans people.

The terms attempted suicide, suicide prevention, suicide*, and suicidal ideation were used to search specifically in relation to suicide. These terms were separated by the operator 'OR'. The trans and suicide related search terms were then conjoined using the 'AND' operator. Where it was possible, search terms were exploded, and were unrestricted.

\section{Selection}

The process of screening the papers is presented in Figure 1. Initial searches returned 2765 papers. Papers were screened by title, then abstract, leaving only 89 papers after 
duplicates were removed. Finally, full-text screening resulted in 30 papers, with no further papers matching all the criteria being identified from their references.

Insert Figure 1 here

The papers identified during full-text screening were excluded if they replicated data from the same sample as another included study (e.g. Testa, Jimenez, \& Rankin, 2014); they were conference abstracts; or the measures of suicidal ideation and attempt were unclear.

\section{Quality Appraisal}

The quality of reporting of the selected studies was established using the STROBE checklist (Strengthening The Reporting of Observational Studies in Epidemiology criteria; Vandenbroucke et al., 2007), and the percentage of the relevant criteria met for each paper was calculated. The quality of reporting among the papers varied considerably from a low of 18\% (Xavier, Bobbin, Singer, \& Budd, 2005) to 76\% (Bauer, et al., 2015) evidencing the highest quality reporting. Most papers scored highly for study design, methodology, and conclusions. Criteria which few met broadly related to how data were treated and analysed, and the provision of sufficient detail at each stage.

\section{Results}

\section{Description of the Studies}

Table 1 describes the main characteristics of the 30 studies reviewed here. The majority of studies $(\mathrm{N}=21)$ were carried out in the USA, with two being carried out in Japan, two in South America (Argentina and Brazil respectively), one in Canada, one in the UK, and 
the remaining three in countries of continental Europe (Belgium; Italy; the Netherlands, Belgium, Germany and Norway).

Insert Table 1 here

A key demographic for this study relates to gender. The papers varied in how they conceptualised their populations, with some representing only those who met diagnostic criteria for gender identity disorder (e.g. Heylens, Elaut, et al., 2014; , Heylens Verroken, et al., 2014; Lobato et al., 2007), and others allowing people to self-define their gender (e.g. Maguen \& Shipherd, 2010; Nemoto, Bodeker, \& Iwamoto, 2011). The definitions that participants could ascribe to were sometimes unclear, however where stated, they differed between studies. For example Goldblum et al. (2012) defined trans people as those "having lived or wanting to live full-time in a gender opposite to their birth or physical sex; having or wanting to physically modify their body to match who they feel they really are inside; or having or wanting to wear the clothing of the opposite sex, in order to express an inner, crossgender identity" (p.470). Alternatively, Nutbrock et al. (2010) defined trans women as assigned "'male' at birth with a later conception of one's self as not 'completely male' in all situations or roles" (p. 14). For some papers it was unclear how their population was defined, or how participants were identified as trans (e.g. Meier, Fitzgerald, Pardo, \& Babcock, 2011). One paper focused solely on trans men (Meier et al., 2011) and four papers on trans women (Nemoto et al., 2011; Nuttbrock et al., 2010; Operario \& Nemoto, 2005; Wilson, Chen, Arayasirikui, Wenzel, \& Raymond, 2014). Sample sizes for individual studies varied from fewer than 100 (Grossman \& D’Augelli, 2007) to over 4000 (Miller \& Grollman, 2015). 
The demographic details reported varied substantially across studies. Age and some form of gender variable were provided by all papers. Given the importance and possible confounding nature of ethnicity or race, and of sexual orientation, it is surprising that many papers omitted these variables. This, together with heterogeneity between papers in important variables (e.g. gender identity; country/culture of origin; how suicidal ideation and attempts were assessed) makes drawing conclusions across studies difficult. This level of variation needs to be borne in mind when considering the findings presented below.

\section{Prevalence of suicidal ideation and attempts}

Prevalence rates amongst all studies varied, however rates remained higher than for the general population, consistent with other studies. In the 17 papers that reported suicidal ideation, rates ranged from 37\% (Mathy, 2003) to 83\% (Testa et al., 2012). Rates of suicide attempt varied widely, ranging from $9.8 \%$ (Heylens, Verroken, et al., 2014) in a mixed trans group to $43 \%$ among trans men only (Meier et al., 2011), and $44 \%$ in a mixed sample (Miller \& Grollman, 2015). High prevalence rates are not entirely surprising for this population group given the extent to which trans people routinely experience minority stress. Recent research (e.g. Grossman, Park, \& Russell, 2016; Lehavot et al., 2016; Tebbe \& Moradi, 2016) indicates a strong association between minority stressors - e.g. prejudice/discrimination, internalised antitrans attitudes, fear of antitrans stigma - and suicidality. As Tebbe and Moradi (2016) suggest, this highlights the importance of considering minority stressors (in addition to general factors) as risk factors for suicide in the trans population.

It is worth noting that the range reported in gender clinics varied from 9.8\% (Heylens, Verroken, et al., 2014b) to 21.2\% (Colizzi, Costa, \& Todarello, 2015), whereas for others it was $11.2 \%$ (Bauer et al., 2015) to 44\% (Miller \& Grollman, 2015). The highest rate from a gender clinic was recorded using a self-report questionnaire (Colizzi et al., 2015), as opposed 
to being gathered through interviews with clinicians directly determining care, which appeared to be the case for the other clinic papers. Suicide attempt may be under-reported in gender clinics as individuals are often aware that it may preclude access to medical transition interventions (Ellis et al., 2015).

\section{Correlates of Suicidal Ideation and Attempts}

A number of demographic variables were associated with higher rates of suicide attempt, such as having a history of incarceration (Clements-Nolle et al., 2006), and lower socioeconomic status (e.g. Goldblum et al., 2012), whilst being in stable housing significantly decreased the odds of a lifetime suicide attempt (Lehavot, Simpson, \& Shipherd, 2016; Marshall et al., 2015). Household income (Perez-Brumer, Hatsenbuehler, Oldenburg, \& Bockting, 2015), relationship status (Maguen \& Shipherd, 2010), sexual orientation (Clements-Nolle et al., 2006) and location (e.g. urban vs. rural area; Goldblum et al., 2012; Marshall et al., 2015; Perez-Brumer et al., 2015) were unrelated to suicide attempt. Variables unrelated to suicidal ideation included religion (Bauer et al., 2015) and relationship status (Terada et al., 2011). For other demographic variables however, relationships appeared mixed or contradictory and will thus be considered in more detail; these included gender, assigned sex, educational attainment, employment, age and ethnicity.

The relationship between suicidal ideation and attempt and gender was complex. House, Van Horn, Coppeans, \& Stepleman (2011) reported that trans people and cis ${ }^{1}$ women had higher rates of lifetime suicide attempt than cis men, and suggested that as most of their trans sample were women (82.3\%), findings may reflect an effect of being female over being male.

Similarly Mathy (2003) found that suicidal ideation in trans people (although again greater than for cis people) was not different to psychosocially matched cis women or cis lesbians. It

\footnotetext{
${ }^{1}$ cis refers to people whose gender identity is the same as the sex they were assigned at birth.
} 
is unclear what the authors of that paper intended in separating cis lesbians from cis women in general, however it could be assumed that the intended demarcation is between cis lesbian women and cis heterosexual women. Furthermore, Goldblum et al. (2012), Lehavot et al. (2016), and Maguen \& Shipherd (2010) found that trans men were more likely to attempt suicide than others with Perez-Brumer et al. (2015) highlighting decreased odds for trans women than for trans men. However, other studies found no differences between different gender identities in terms of ideation (Hoshiai et al., 2010; Heylens, Elaut, et al., 2014) or attempts (Clements-Nolle et al., 2006; Maguen \& Shipherd, 2010; Marshall et al., 2015), and House et al. (2011) found trans women were more at risk of suicide attempt. There are important differences between the studies in terms of how participants were defined, where and how data were collected and gathered, and in the sizes of different trans populations included, and issues with comparing disaggregated cis people to mixed trans groups. Thus although trans people consistently had higher rates of suicidal ideation and attempt than cis people as a group, this relationship was not simple, and variations existed in sub-populations of each group.

Being assigned female rather than male at birth related to higher levels of suicidal ideation (Xavier, Bobbin, Singer, \& Budd., 2005), and suicide attempt (Goldblum et al., 2012; Maguen \& Shipherd, 2010). However in Skagerberg, Parkinson and Carmichael's (2013 study sex assigned at birth was found not to be related to suicide attempt. However, these data were from clinic records rather than from participants, which may have affected the results in that participants may have purposefully minimised any difficulties out of concern of a potential impact on their access to treatment. Furthermore, their population was children and young people, who may not have made as many attempts as adults. If being female assigned at birth relates to suicidal ideation and attempt, this may relate to the findings above, perhaps implying that others' perceptions of gender (regardless of an individual's 
identity) may lead to distressing experiences. However there are differences in the assigned sex composition of the samples in these papers which make it difficult to draw firm conclusions.

Educational status appeared unrelated to suicidal ideation (Clements-Nolle et al., 2006) or suicide attempt (Clements-Nolle et al., 2006; Marshall et al., 2015), however PerezBrumer et al (2015) did find that greater educational attainment related to decreased odds of lifetime suicide attempt. This may be an artefact of differences in the way educational attainment was coded, and further exploration would be useful.

Clements-Nolle et al. (2006) found that unemployment related to greater risk of suicide attempt, however Marshall et al. (2015) and Terada et al (2011) found that it was not related to suicide attempt or suicidal ideation respectively. As such the relationship between unemployment and suicide is unclear.

Age was another factor where there appeared to be considerable variation in findings. In terms of suicide attempt, Marshall et al. (2015) and Perez-Brumer et al (2015) found no relationship with age, whereas Goldblum et al (2012), Maguen and Shipherd (2010), and Nuttbrock et al. (2010) all found that younger age related to an increase in risk of suicide attempt. However this relationship was not apparent for suicidal ideation. Terada et al. (2011) found that ideation was related to younger age among trans women, but age was unrelated in trans men. This may be at least partly explained by the results of Xavier et al. (2005) which demonstrated that suicidal ideation was very high among those who were $13-19$, then decreased substantially until around the age of 30, when it increased again. In Terada et al's (2011) sample, $58 \%$ of the trans women were over 30 compared to $26 \%$ of the trans men. Furthermore only $26 \%$ of the trans women were under 24 , whereas $42 \%$ of the trans men were under 24. Across all papers, the age profiles of participants differed, which may have 
contributed to the differences in findings, given that the relationship between age and suicidal ideation and attempt does not appear to be linear.

The relationship between suicidal ideation and ethnicity/race was relatively straightforward. Being White related to the highest levels of suicidal ideation (Kenagy \& Bostwick, 2005; Nemoto et al., 2011) with African Americans being significantly less likely than others to disclose ideation (Xavier et al., 2005). For suicide attempt the evidence was conflicted, with one study finding an increase related to being White (Clements-Nolle et al., 2006), compared to others finding multiracial and 'other' groups, or those who were 'nonWhite', reporting higher rates of suicide attempt than White people (Goldblum et al., 2012; Perez-Brumer et al., 2015). Furthermore Maguen and Shipherd (2010) and Nemoto et al. (2011) found no relationship between ethnicity and suicide attempt, and the relationship highlighted in Perez-Brumer et al. (2015) for lifetime attempts was not present for attempts within the past 12 months. There may be differences between the samples which could affect these findings. For example, having a larger White cohort in one study (Goldblum et al., 2012) may have influenced the outcomes when compared to a study with a smaller White group and greater representation of people from other races (Clements-Nolle et al., 2006). However, one study that found no relationship between ethnicity and suicide attempt utilised a sample that was almost exclusively White (Maguen \& Shipherd, 2010; 97\% White).

\section{Suicidality and Mental health}

Increased risks for ideation were seen in those who had a history of abuse (Grossman \& D’Augelli, 2007), and in people with past or current use of either psychotherapy or medication (Mathy, 2003). Suicide attempt was related to having a history of drug or alcohol treatment (Clements-Nolle et al., 2006) and to psychiatric hospitalisation even when demographic factors had been accounted for (Maguen \& Shipherd, 2010), although a history 
of hospitalisation only predicted variance in attempts once victimisation-related variables were accounted for in the model. Higher rates of suicide attempt were evident in people with a diagnosis of dissociative identity disorder (Colizzi et al., 2015) and in those with low selfesteem (Clements-Nolle et al., 2006). No relationship was found between impulse control difficulties and either suicidal ideation and attempt (Mathy, 2003), or having a diagnosed disorder (from Axis II of the Diagnostic and Statistical Manual, $4^{\text {th }}$ edition; American Psychiatric Association, 2000) and suicide risk (Heylens, Elaut, et al., 2014). Depression was related to increased suicidal ideation (Nemoto et al., 2011) and suicide attempt (ClementsNolle et al., 2006). Help-seeking for distress was increased in those who were experiencing suicidal ideation, however there were no differences between those seeking help for distress and those not treatment-seeking in terms of suicide attempt (Effrig, Bieschke, \& Locke, 2011). House et al. (2011) found that psychiatric comorbidity was related to increased ideation in trans men, but not in trans women, however the sample comprised of a substantially larger group of trans men than trans women.

\section{Trans Related Variables and Suicidality}

Many of the variables studied related to experiences that people had as a direct consequence of being trans. Suicide-negativity (an index formed of questions relating to suicidal thoughts or feelings in relation to being LGBT; Grossman \& D’Augelli, 2007) was associated with higher rates of suicidal ideation. Conformity with behaviours consistent with those expected based on the sex someone was assigned at birth (Grossman \& D'Augelli, 2007), and age of onset of 'gender dysphoria' (Heylens, Elaut, et al., 2014), were not associated with suicidal ideation and attempt.

There was a complicated relationship between suicidal ideation and attempt and social support, which was mainly explored in Bauer et al. (2015). Having high levels of support was 
found to be strongly related to decreased suicidal ideation and attempt. When explored in more detail, there was no relationship between social support from people who were not the participants' parents and suicidal ideation; however support from parents was related to decreased ideation. Unexpectedly, the authors found a positive relationship between higher levels of social support from leaders (e.g. employers or teachers) and increased suicide attempt, which they suggest may be due to attempts instigating increased support from those around the person, rather than causing it.

Bauer et al. (2015) demonstrated no relationship between undergoing some form of social transition and suicidal ideation. They did however find that having changed identity documents to match the gender someone identified as did relate to decreased suicidal ideation and attempt. When transition was defined as "living full-time in your gender of choice" (Rood, Puckett, Pantalone, \& Bradford, 2015, p. 271,), those planning to transition socially, or who had already socially transitioned had elevated odds of reporting suicidal ideation compared to those who had no intention of transitioning. There was however a significant interaction between stage of transition and experiences of discrimination, whereby the greatest odds of reporting lifetime ideation resulted from planning to or having undergone transition, and experiencing discrimination, while the lowest odds were among those who did not plan to transition and who did not experience discrimination.

Medical transition was similarly complex. Accessing transition-related medical care (or not) did not appear to relate to suicide attempt among trans women (Wilson et al., 2014). Heylens, Verroken et al. (2014) also reported that in those who attended a gender clinic and underwent a medical transition, lifetime suicide attempt was not affected. However this may be because lifetime rates are historical and cannot decrease. That they did not increase suggests that the interventions may have had an impact. However, one person did complete suicide during the pre- and post-intervention measurements, which was not explored by the 
authors as their data were excluded. It is important that findings from the gender clinics are considered with reference to their context as mediating access to medical interventions. In contrast however Bauer et al. (2015) reported less suicidal ideation for those undergoing a medical transition compared to those who were considering it. They further found that among those who were contemplating suicide, rates of suicide attempt increased during transition compared to other stages. There are differences in how medical transition was defined within these papers which may account for some of this discrepancy; however the samples were drawn from different populations (in terms of country location, as well as community vs. clinic) which may also limit comparison. Finally, being in a later stage of therapy (referring to an individual's medical process of transition) when presenting for an initial appointment at a gender clinic was related to increased suicidal ideation among trans women, but not trans men (Terada et al., 2011).

In terms of the specific medical interventions that people might undergo, Meier et al. (2011) found a small but non-significant decrease in lifetime prevalence of suicide attempt between a group of trans men who were taking hormones compared to those who were not. Wilson et al. (2014) found that hormones related to a significantly lower rate of suicidal ideation in trans women receiving them, compared to those who were not. Overall Bauer et al. (2015) reported that receiving hormones was associated with decreased suicidal ideation in a mixed group compared to those who had not started hormone therapy. Wilson et al. (2014) also studied breast augmentation among trans women and found that it related to lower levels of ideation in those who had undergone the procedure compared to those who had not, whereas whether genital surgery had been undertaken or not was unrelated to suicide attempt.

\section{Negative interpersonal experiences.}


In general, experiencing lower levels of internalised transphobia related to lower levels of ideation (Bauer et al., 2015) and attempts (Bauer et al., 2015; Marshall et al., 2015; Perez-Brumer et al., 2015; although for Perez-Brumer et al., 2015 the relationship between internalised transphobia and suicide attempt became non-significant when referring to attempts within the past 12 months). Experiences of gender-related discrimination related to increased odds of suicidal ideation (Rood et al., 2015), although there was an interaction with transition as discussed above) and suicide attempt (Clements-Nolle et al., 2006; Miller \& Grollman, 2015). Lower levels of external transphobia related to lower levels of suicidal ideation and attempt (Bauer et al., 2015), while experiencing verbal victimisation (ClementsNolle et al., 2006) and gender-based victimisation in school (Grossman \& D’Augelli, 2007) all related to an increased risk of suicide attempt. For example, discrimination from healthcare staff and from the police related to increased odds of a lifetime attempt, although this did not hold when part of a multivariate model where internalised stigma remained significant (Marshall et al., 2015). Structural stigma (e.g. an environment with non-equal legislation for trans people) was also related to increased odds of lifetime attempts, however not to attempts within the past 12 months.

Interestingly, being seen by others as gender nonconforming was significantly related to increased odds of lifetime suicide attempt, even when other variables were accounted for. However this relationship was not present when transphobic discrimination was incorporated into the model. Thus transphobic discrimination at least partly mediated the relationship between gender nonconformity and lifetime suicide attempt (Miller \& Grollman, 2015).

Being victimised verbally (Clements-Nolle et al., 2006), subject to sexual violence (Clements-Nolle et al., 2006; Testa et al., 2012), or physical violence (Clements-Nolle et al., 2006; Maguen \& Shipherd, 2010; Testa et al., 2012) also related to an increased risk of suicide attempt. However Testa et al. (2012) found that the relationship between violence and 
identity may be more nuanced for suicidal ideation. Specifically, that for trans women physical violence related to increased ideation whereas sexual violence did not; while for trans men the converse was true with sexual violence relating to increased ideation and there being no relationship with physical violence. Having experienced physical or sexual violence related to suicidal ideation in Rood et al. (2015), with experiences of both associated with the highest odds of reporting ideation.

\section{Discussion}

The purpose of this paper was to systematically review the published research on suicidality (i.e. suicidal ideation and attempt) in trans populations. The literature reviewed here consistently reports rates of suicide among trans people as being substantially higher than for the general population; although reported rates vary considerably between studies.

Across the literature reviewed, some demographic variables typically associated with suicidal ideation and attempts in the general population were found not to be associated with suicidality in trans people. For example, in the general population a relationship has been found between suicidal ideation and factors such as religious affiliation, relationship status and lower levels of education (e.g. see Dervic et al., 2004; Lorant, Kunst, Huisman, Costa, \& Mackenbach, 2005; Nock et al., 2008) yet in the studies reviewed there is limited evidence that these factors are related to suicidal ideation. There was also considerable inconsistency between the findings of different studies as to whether or not there was a relationship between suicidality and variables such as gender identity, sex assigned at birth, employment, age, and ethnicity.

The extent to which these findings appear contradictory suggest that a more nuanced exploration of the relationship between these factors and suicidality in the trans population is warranted. In particular, there is a lack of clarity around the extent to which particular risk 
factors may differentially impact on trans people as a function of key gender-related variables (e.g. sex assigned at birth; stage of transition; etc). For example, some trans people whose gender identity and/or appearance is less congruent with established social norms, may face ostracisation and/or victimisation due to other's intolerance of this, and these experiences may leave them at increased risk of suicide.

In relation to mental health, high rates of psychiatric diagnoses have been identified as associated with increased suicide risk in many populations (e.g. Qin, Agerbo, \& Mortensen, 2003), including mixed LGBT groups (Irwin et al., 2014). Mental health related factors showed similar relationships here. For example hospitalisation is a significant suicide risk factor in the general population (Bostwick \& Pankratz, 2000), and was also identified as a risk factor for suicide attempt in the trans population. In addition, a recent study (Tebbe \& Moradi, 2016) has suggested that in the trans population depression is a mediating factor for suicide risk due to minority stress.

The complex, and sometimes contradictory findings concerning demographic and mental health variables in these studies, suggests that their relationships with suicidal ideation and attempt in trans communities are either different, or more complex, among trans people than in many other groups. This may be because of the additional pressures facing trans people conferred by virtue of their gender minority status.

In-line with models of minority stress (Meyer, 2003; Riggs \& Treharne, 2016) these findings highlighted that discrimination and violence were consistently related to suicidal ideation and attempt in trans populations. Clements-Nolle (2006) noted that many variables relating to suicide were similar as for those with LGB people, "societal risk factors such as [trans-related] gender-based discrimination and victimization are independently associated with attempted suicide" (p. 63). Furthermore, discrimination accounted for the relationship 
found between being perceived as gender nonconforming and suicide attempt (Miller \& Grollman, 2015), and was a factor in the relationship between suicidal ideation and transition status (Rood et al., 2015). The relationship between discrimination and negative outcomes was present at both the individual level (e.g. through interpersonal victimisation) and at the structural environmental level (e.g. through policy and legislation). However as with other variables, gender differences did emerge with physical and sexual trans-related violence having different impacts for trans men and trans women. Even so, gender differences in suicidality within the trans population have been underexplored; and where studied, explanations for these patterns are unclear.

Testa et al., (2015) highlighted how distal variables, such as discrimination, may involve different stressors for trans people when compared to LGB people. For example, difficulties accessing legal recognition documents, accessing gender appropriate medical care, or being unsafe in gendered spaces. They further posited an additional variable of "nonaffirmation' of identity. In relation to these factors, supporting people to live in a manner consistent with their gender, or affirming their identities legally through the provision of documentation or access to needed interventions, tended to relate to decreased suicidal ideation and attempt. However it may be that people who were less distressed were more able to facilitate the changes they wished to make. Some aspects of physical transition were more complex, for example although being in the process of transition was related to suicide attempts, this relationship involved other factors such as discrimination. The variation in specific types of interventions that are either protective (e.g. hormone therapy; Bauer et al, 2015) or non-related (e.g. genital surgery; Wilson et al., 2014) may be a reflection of those that help the person interact in the world on a daily basis as the gender they are, compared to those that are more about internal consistency (thus the difference between the impact of hormones vs. genital surgery). Rood et al. (2015) demonstrated that undergoing or having 
undergone transition related to greater risks of lifetime ideation than for those not wanting to undergo transition. The authors suggested that their finding of an interaction between transition and discrimination may imply that transition confers a vulnerability to increased discrimination, thus explaining this interaction. Similarly Bauer et al (2015) suggested that although transition ultimately reduced risk, while undergoing it participants may face significant challenges which could add to their overall stress burden. This is commensurate with other research (Bailey et al., 2014) which showed that having undergone transition or being in the process of transition reflected a lower risk than being prevented from transitioning.

Protective factors in the minority stress model largely relate to feeling connected to, and part of a community, having social support, and a sense 'identity pride'. Here, identitydevelopment related factors were unrelated to suicide (e.g. childhood gender conformity; Grossman \& D’Augelli, 2007), although knowing people who were trans when first identifying as such seemed to be of some benefit, possibly through providing a positive concept of trans identities (Goldblum et al., 2012). Furthermore, having high levels of social support generally, and in particular parental social support, were protective in terms of suicide risk (Bauer et al., 2015). This finding echoes other research with trans populations which found that rejection from family and peers increased the risk of suicide attempt (Haas, Rodgers, \& Herman, 2014), and findings from studies with many other marginalised populations (e.g. Compton, Thompson, \& Kaslow, 2005; Farrell, Bolland, \& Cockerham, 2015).

\section{Limitations and Considerations for Research and Policy}

Distal stressors and social support have been studied in relation to suicidal ideation and attempt among trans groups, and the findings so far are consistent with those suggested 
by Meyer's (2003) minority stress theory. However, it would be useful to explore other minority stress factors, such as proximal factors (e.g. internalised transphobia, concealment), and protective factors (e.g. identity pride), to identify whether these variables can support a more cohesive understanding of suicide risk among trans people. That a substantial number of trans-specific and gender-based victimisation variables related to suicidal ideation and attempt (as protective and risk factors) demonstrates the added complexity of suicide risk in trans people over and above that experienced by the general population. Although models of minority stress (e.g. Meyer, 2003; Riggs \& Treharne, 2016) offer valuable insights into additional factors impacting on trans suicide, the inclusion of other suicide models (e.g. Interpersonal Psychological Theory or the Clinical Model; see Ploderl et al., 2014) may help us to better understand the impact of non-minority specific factors on suicidality in trans people; and offer opportunities for more accurate comparison with general population samples.

One of the main barriers to understanding trans suicidality is the wide variation of samples and measures across the set of studies reviewed. For example, studies frequently used a mixture of validated (although it was not clear whether these had been validated for trans people) and researcher-designed measures; and data collection varied from interviewer delivered surveys, to computer based delivery, and clinical diagnostic assessments. Similarly, with some studies targeting samples from very specific subgroups of the whole trans community and others aggregating data from across the trans population as a whole, there was a great deal of inconsistency in the samples. This level of variation adds too much complexity to the field, making it difficult to draw firm conclusions by cross-study comparison. Furthermore, the lack of clarity around correlates of suicidality, particularly gender, in the trans population, suggests that a key consideration for future research is the avoidance of aggregating all trans people together. There is ample research evidence that 
different subgroups have variable experiences of the world as a function of factors such as gender identity and stage of transition (e.g. see Ellis et al., 2014; Ellis et al., 2016). It is also important to ensure that the experiences of trans people with non-binary gender identities are appropriately included. Typically, non-binary people have either been omitted from the research or subsumed into other categories. Given the central role that binary gender plays in the organisation of cis-centric society, specific attention to gender - and the experiences of those with a non-binary gender identity in particular - could make a substantive contribution to our understanding of suicidality in the trans population as a whole.

As with the majority of work in the field of suicidality, the papers reviewed here focussed on suicidal ideation and attempt rather than completed attempts. Gathering reliable data on completed suicides within the trans population would provide a more complete picture of trans suicide; perhaps shedding light on which subgroups of the trans population are at greatest risk. Currently data on completed trans suicides is not readily available as a person's trans status is seldom recorded in coronial data.

In terms of the review methodology, only English language papers were included, and within the studies there was a bias towards English-speaking participants and locations; and towards the US in particular. These issues may have impacted upon the data, for example, Hjelmeland (2011) emphasised the need to take culture into account within suicide research. There are also differences in how trans people are viewed and treated (socially, legally and medically) between different locations, which make it difficult to draw comparisons. Ideally future research should involve liaison and joint working with trans organisations from a range of locations and countries, to explore the cultural meanings of trans-people's experiences.

Finally, an important consideration in light of the studies herein relates to cisnormativity (the tendency to assume that being cisgender is normative, and being 
transgender is therefore abnormal). Many papers referred to trans people by their assigned gender, which is disrespectful of the individuals the authors purported to be concerned with. Trans people were also compared to 'men' and 'women' rather than cis men or cis women, making their identities as men, women or other non-binary identities 'other' to the 'norm'. Othering constitutes a microaggression, which ironically forms part of the complex interaction of factors contributing to poor mental health in trans people (e.g. Nadal, 2013). Therefore, greater care needs to be taken in future research both to refer to gender appropriately and importantly, to specifically explore the part that 'othering' and 'misgendering' potentially play in mental wellbeing.

For future policy development, it is clear that lived experiences of discrimination and victimisation have a substantial and devastating impact on trans people's lives. There are many areas where policy must be amended to improve inclusion and reduce discrimination of trans people. In particular, health policy needs reviewing, to enable trans people to more readily self-identify and access the support that they need (see McNeil et al., 2012; Bailey et al., 2014). This is important for commissioners, who also need to consider wider sources of research (for example, research coming from the trans communities themselves) to avoid only being exposed to one dominant perspective which does not necessarily reflect the identities and realities of those for whom they may commission services.

\section{Implications for Mental Health Practitioners}

For psychologists, counsellors, and others working with trans clients in the mental health space, these findings highlight the need to respond effectively and in a timely manner to suicidality. Rather than being an indicator of an underlying mental illness, suicidality in the trans population would appear to be attributable to unbearable stress resulting from a complex mix of risk factors (e.g. discrimination and victimisation, social exclusion, identity 
concealment, internalised transphobia, decompensation) and a relative absence of protective factors (cf. Jobes, 2006). The focus of therapy therefore needs to be on working collaboratively with trans clients focusing specifically on these issues and supporting them to develop resistance. However, given the substantial, and potentially immediate, risk of suicidality in this population it is essential to gain an understanding of these underlying issues and assess suicide risk at the earliest opportunity. The Collaborative Assessment and Management of Suicidality (or CAMS) model (Jobes, 2006) is a well-fitted approach to risk assessment and treatment planning in cases of this kind. An ecological approach to therapy (e.g. see Wilson, 2012) would also be useful for working with clients to build resilience and coping.

While much can be accomplished in working with gender-diverse people at an individual level it is important to also facilitate structural change. We may therefore consider moving beyond one-to-one work and therapeutic interventions which locate difficulties within the individual, to also working creatively in fostering social support, and in tackling the social causes of these disparities which lie almost exclusively outwith individual members of the trans community. As therapists we have an ethical duty to challenge practice which may cause harm, such as delaying access to interventions to support gender affirmation or offering reparative or 'conversion' therapies in relation to gender, and to ensure our practice does not inadvertently recreate the minority stressors experienced by trans clients in other settings (cf. Ellis et al., 2015).

Our recommendations are further echoed by professional practice guidance from the USA and the UK. Both the American Psychological Society's Guidelines for Psychological Practice with Transgender and Gender Nonconforming People (2015), and the British Psychological Society's Guidelines and Literature Review for Psychologists Working Therapeutically with Sexual and Gender Minority Clients (2012) place a similar emphasis on 
the importance of practicing in a trans affirmative and culturally competent manner. In working with gender diverse people, this would include recognition of and value for nonbinary identities, the importance of intersectionality, the value of reflection on one's own biases (and the potential impact of those biases), challenging social inequalities and enhancing trans affirmative environments. Clearly then, both the current evidence base and professional best practice point to the necessity of working at all levels, above that of one-toone work directly with the individual, as an important strategy in improving individual client and community outcomes.

\section{Conclusion}

The findings presented here suggest that suicidality among trans people is incredibly complex; relating to multiple individual, systemic and structural factors. It cannot be located solely within the individual, and any exploration of this must consider intersectional sources of oppression to fully capture its nuances.

To progress our understanding of suicidality in trans people, models such as Testa et al's (2015) adapted Minority Stress Hypothesis and Riggs and Treharne's (2016) theory of 'Decompensation' offer a good starting point. However a great deal more high quality, thoughtful, and well-described research is required. In particular, greater attendance to group differences within the trans population is needed to help unpick some of the apparent contradictions between studies in the existing literature.

Ultimately the use of models around trans suicidality, and the consideration of factors which may or may not contribute to it is only useful practically if it has a real-world impact in reducing distress and suicidality among gender diverse people feel. It is clear at this stage that discrimination and victimisation, both interpersonally and at a societal level, have a substantial role in suicidality. We can act on this now, to effect positive change, improve 
resilience factors such as access to and inclusion in trans organisations, and potentially save lives. 


\section{References}

References marked with an asterisk are those which are included in the systematic review.

American Psychiatric Association (2000). Diagnostic and statistical manual of mental disorders (4th Edition, Text Revision). APA.

American Psychological Association (2015). Guidelines for psychological practice with transgender and gender nonconforming people. American Psychologist, 70(9), 832864. Retrieved 01/06/2017 from http://www.apa.org/practice/guidelines/transgender.pdf

Bailey, L., Ellis, S. J. \& McNeil, J. (2014). Suicide risk in the UK trans population and the role of gender transition in decreasing suicidal ideation and suicide attempt. Mental Health Review Journal, 19(4), 209-220. doi:10.1108/MHRJ-05-2014-0015.

Bauer, G. R., Pyne, J., Francino, M.C., \& Hammond R. (2013). La suicidabilité parmi les personnes transe en Ontario: Implications en travail social et en justice sociale. Service Social, 59(1), 35-62. Retrieved from http://transpulseproject.ca/research/suicidality-among-trans-people-in-ontario-lasuicidabilite-parmi-les-personnes-trans-en-ontario/.

*Bauer, G. R., Scheim, A. I., Pyne, J., Travers, R. \& Hammond, R. (2015). Intervenable factors associated with suicide risk in transgender persons: A respondent driven sampling study in Ontario, Canada. BMC Public Health, 15, 525. doi:10.1186/s12889-015-1867-2.

Bostwick, J. M. \& Pankratz, V. S. (2000). Affective disorders and suicide risk: A reexamination. American Journal of Psychiatry, 157(12), 1925-1932. doi:10.1176/appi.ajp.157.12.1925. 
British Psychological Society (2012). Guidelines and literature review for psychologists working therapeutically with sexual and gender minority clients. Retrieved 23/02/16 from http://shop.bps.org.uk/guidelines-and-literature-review-for-psychologistsworking-therapeutically-with-sexual-and-gender-minority-clients.html.

*Clements-Nolle, K., Marx, R. \& Katz, M. (2006). Attempted suicide among transgender persons. Journal of Homosexuality, 51(3), 53-69. doi:10.1300/J082v51n03_04.

*Colizzi, M., Costa, R. \& Todarello, O. (2015). Dissociative symptoms in individuals with gender dysphoria: Is the elevated prevalence real? Psychiatry Research, 226, 173-180. Retrieved from Science Direct, July 2015.

Compton, C. T., Thompson, N. J. \& Kaslow, N. J. (2005). Social environment factors associated with suicide attempt among low-income African Americans: The protective role of family relationships and social support. Social Psychiatry and Psychiatric Epidemiology, 40(3), 175-185. Retrieved from Springer Link database; http://link.springer.com/article/10.1007/s00127-005-0865-6.

del pozo de Bolger, A., Jones, T., Dunstan, D. \& Lykins, A. (2014). Australian trans men: Development, sexuality, and mental health. Australian Psychologist, 49, 395402. doi:10.1111/ap.12094.

Dervic, K., Oquendo, M. A., Grunebaum, M. F., Ellis, S., Burke, A. K. \& Mann, J. J. (2004). Religious affiliation and suicide attempt. American Journal of Psychiatry, 161, 2303-2308. Retrieved from https://www.researchgate.net/profile/Maria_Oquendo3/publication/8157488_Religiou s_affiliation_and_suicide_attempt/links/00463521c8126c594f000000.pdf. 
*Effrig, J. C., Bieschke, K. J. \& Locke, B. D. (2011). Examining victimization and psychological distress in transgender college students. Journal of College Counseling, 14, 143-157. doi:10.1002/j.2161-1882.2011.tb00269.x.

Ellis, S. J., Bailey, L. B. \& McNeil, J. (2015). Trans people's experiences of mental health and gender identity services: A UK study. Journal of Gay \& Lesbian Mental Health, 19(1), 4-20. doi:10.1080/19359705.2014.960990.

Ellis, S. J., Bailey, L. \& McNeil, J. (2016). Transphobic victimisation and perceptions of future risk: A large-scale study of the experiences of trans people in the UK. Psychology \& Sexuality, 7 (3), 211-224. doi: 10.1080/19419899.2016.1181669.

Farrell, C. T., Bolland, J. M. \& Cockerham, W. C. (2015). The role of social support and social context on the incidence of attempted suicide among adolescents living in extremely impoverished communities. Journal of Adolescent Health, 56(1), 59-65. doi:10.1016/j.jadohealth.2014.08.015.

Friedman, R. C. (1999). Homosexuality, psychopathology and suicidality. Archives of General Psychiatry, 56, 887-888.

*Goldblum, P., Testa, R. J., Pflum, S., Hendricks, M. L., Bradford, J. \& Bongar, B. (2012). The relationship between gender-based victimization and suicide attempts in transgender people. Professional Psychology: Research and Practice, 43(5), 468475. doi:10.1037/a0029605.

*Grossman, A. H. \& D'Augelli, A. R. (2007). Transgender youth and life-threatening behaviors. Suicide and Life-Threatening Behavior, 37(5), 527-537. doi:10.1521/suli.2007.37.5.527. 
*Grossman, A. H., Park, J. Y. \& Russell, S. T. (2016). Transgender youth and suicidal behaviours: applying the interpersonal psychological theory of suicide. Journal of Gay and Lesbian Mental Health, 20(4), 329-349. doi: 10.1080/19359705.2016.1207581.

Haas, A. P., Eliason, M., Mays, V. M., Mathy, R. M., Cochran, S. D., D'Augelli, A. R., Silverman, M. M., Fisher, P. W., Hughes, T., Rosario, M., Russell, S. T., Malley, E., Reed, J., Litts, D. A., Haller, E., Sell, R. L., Remafedi, G., Bradford, J., Beautrais, A. L., Brown, G. K., Diamond, G. M., Friedman, M. S., Garofalo, R., Turner, M. S., Hollibaugh, A. \& Clayton, P. J. (2010). Suicide and suicide risk in lesbian, gay, bisexual, and transgender populations: Review and recommendations. Journal of Homosexuality, 58(1), 10-51. doi:10.1080/00918369.2011.534038.

Haas, A. P., Rodgers, P. L. \& Herman, J. L. (2014). Suicide attempts among transgender and gender non-conforming adults: Findings of the national transgender discrimination survey. Retrieved July 2015 from http://williamsinstitute.law.ucla.edu/wpcontent/uploads/AFSP-Williams-Suicide-Report-Final.pdf.

*Heylens, G., Elaut, E., Kreukels, B. P. C., Paap, M. C. S., Cerwenka, S., Righter-Appelt, H., Cohen-Kettenis, P. T., Haraldsen, I. R. \& De Cuypere, G. (2014a). Psychiatric characteristics in transsexual individuals: Multicentre study in four European countries. The British Journal Of Psychiatry, 204, 151-156. doi:10.1192/bjp.bp.112.121954.

*Heylens, G., Verroken, C., De Cock, S., T'Sjoen, G \& De Cuypere, G. (2014b). Effects of different steps in gender reassignment therapy on psychopathology: A prospective study of persons with a gender identity disorder. Journal of Sexual Medicine, 11, 119-126. doi:10.1111/jsm. 12363. 
Hjelmeland, H. (2011). Cultural context is crucial in suicide research and prevention. Crisis, 32, 61-64. doi:10.1027/0227-5910/a000097.

*Hoshiai, M., Matsumoto, Y., Sato, T., Ohnishi, M., Okabe, N., Kishimoto, Y., Terada, S. \& Kuroda, S. (2010). Psychiatric comorbidity among patients with gender identity disorder. Psychiatry And Clinical Neurosciences, 64, 514-519. doi:10.1111/j.1440-1819.2010.02118.x.

*House, A. S., Van Horn, E., Coppeans, C. \& Stepleman, L. M. (2011). Interpersonal trauma and discriminatory events as predictors of suicidal and nonsuicidal self-injury in gay, lesbian, bisexual, and transgender persons. Traumatology, 17(2), 75-85. doi:10.1177/1532765610395621.

International Association for Suicide Prevention (2012). World suicide prevention day: Facts and figures. Retrieved from www.iasp.info/wspd/pdf/2012_wspd_facts_and_figures.pdf.

Irwin, J. A., Coleman, J. D., Fisher, C. M. \& Marasco, V. M. (2014). Correlates of suicide ideation among LGBT Nebraskans. Journal of Homosexuality, 61(8), 1172-1191. doi:10.1080/00918369.2014.872521.

Jobes, D. A. (2006). Managing suicidal risk: A collaborative approach. New York: The Guilford Press.

*Kenagy, G. P. \& Bostwick, W. B. (2005). Health and social service needs of transgender people in Chicago. International Journal of Transgenderism, 8(2-3), 57-66. doi:10.1300/J485v08n02_6. 
*Lehavot, K., Simpson, T. L. \& Shipherd, J. C. (2016). Factors associated with suicidality among a national sample of transgender veterans. Suicide and Life-threatening Behavior, 46(5), 507-524. doi: 10.1111/sltb.12233

*Lobato, M. I., Koff, W. J., Schestatsky, S. S., de Vasconcellos Chaves, C. P., Petry, A., Crestana, T., Amaral, J. T., de Quadros Onofrio, F., Salvador, J., Silveria, E. \& Henriques, A. A. (2007). Clinical characteristics, psychiatric comorbidities and sociodemographic profile of transsexual patients from an outpatient clinic in Brazil. International Journal of Transgenderism, 10(2), 69-77. doi:10.1080/15532730802175748.

Lorant, V., Kunst, A. E., Huisman, M., Costa, G. \& Mackenbach, J. (2005). Socio-economic inequalities in suicide: A European comparative study. The British Journal of Psychiatry, 187(1), 49-54. doi:10.1192/bjp.187.1.49.

*Maguen, S. \& Shipherd, J. (2010). Suicide risk among transgender individuals. Psychology \& Sexuality, 1(1), 34-43. doi:10.1080/19419891003634430.

Marshall, E., Claes, L., Bouman, W. P., Witcomb, G. L. \& Arcelus, J. (2016). Non-suicidal self-injury and suicidality in trans people: A systematic review of the literature. International Review of Psychiatry, 28(1), 58-69. doi:10.3109/09540261.2015.1073143.

*Marshall, B. D., Socías, M. E., Kerr, T., Zalazar, V., Sued, O. \& Arístegui, I. (2015). Prevalence and correlates of lifetime suicide attempts among transgender persons in Argentina. Journal of Homosexuality. doi:10.1080/00918369.2015.1117898. 
*Mathy, R. M. (2003). Transgender identity and suicidality in a nonclinical sample. Journal of Psychology \& Human Sexuality, 14(4), 47-65. doi:10.1300/J056v14n04_03.

McNeil, J., Bailey, L., Ellis, S. J., Morton, J. \& Regan, M. (2012). Trans mental health study. Edinburgh: The Scottish Transgender Alliance. Available at http://www.traverseresearch.com/wp-content/uploads/2012/12/Trans-Mental-Health2012.pdf.

*Meier, S. L. C., Fitzgerald, K. M, Pardo, S. T. \& Babcock, J. (2011). The effects of hormonal gender affirmation treatments on mental health in female-to-male transsexuals. Journal of Gay \& Lesbian Mental Health, 15(3), 281-299. doi:10.1080/19359705.2011.581195.

Meyer, I. H. (2003). Prejudice, social stress, and mental health in lesbian, gay, and bisexual populations: Conceptual issues and research evidence. Psychological Bulletin, 129(5), 674-697. Retrieved July 2015 from http://www.ncbi.nlm.nih.gov/pmc/articles/PMC2072932/pdf/nihms32623.pdf.

*Miller, L. R. \& Grollman, E. A. (2015). The social costs of gender nonconformity for transgender adults: Implications for discrimination and health. Sociological Forum, 30(3), 809-831. doi:10.1111/socf.12193.

Mościcki, E. K., (2001). Epidemiology of completed and attempted suicide: Toward a framework for prevention. Clinical Neuroscience Research, 1(5), 310-323. doi:10.1016/S1566-2772(01)00032-9. 
Nadal, K. L. (2013). That's so gay! Microaggressions and the lesbian, gay, bisexual, and transgender community. Contemporary perspectives on lesbian, gay, and bisexual psychology. Washington, DC, US: American Psychological Association.

*Nemoto, T., Bodeker, B. \& Iwamoto, M. (2011). Social support, exposure to violence and transphobia, and correlates of depression among male-to-female transgender women with a history of sex work. American Journal of Public Health, 101(10), 1980-1988. doi:10.2105/AJPH.2010.197285.

Nock, M. K., Borges, G., Bromet, E. J., Alonso, J., Angermeyer, M., Beautrais, A., Bruffaerts, R., Chiu, W. T., de Girolamo, G., Gluzman, S., de Graaf, R., Gureje, O., Haro, J. M., Huang, Y., Karam, E., Kessler, R. C., Lepine, J. P., Levinson, D., Medina-Mora, M. E., Ono, Y., Posada-Villa, J. \& Williams, D. (2008). Crossnational prevalence and risk factors for suicidal ideation, plans and attempts. The British Journal of Psychiatry, 192(2), 98-105. doi:10.1192/bjp.bp.107.040113.

*Nuttbrock, L., Hwahng, S., Bockting, W., Rosenblum, A., Mason, M., Macri, M. \& Becker, J. (2010). Psychiatric impact of gender-related abuse across the life course of male-to-female transgender persons. Journal of Sex Research, 47(1), 12-23. doi:10.1080/00224490903062258.

*Operario, D. \& Nemoto, T. (2005). Sexual risk behavior and substance use among a sample of Asian Pacific Islander transgender women. AIDS Education And Prevention, 17(5), 430-443. doi:10.1521/aeap.2005.17.5.430.

*Perez-Brumer, A., Hatzenbuehler, M. L., Oldenburg, C. E. \& Bockting, W. O. (2015). Individual- and structural-level risk factors for suicide attempts among transgender adults. Behavioural Medicine, 41(3), 164-171. doi:10.1080/08964289.2015.1028322. 
Ploderl, M., Sellmeier, M., Fartacek, C., Pichler, E-M., Fartacek, R. \& Kralovec, K. (2014). Explaining the suicide risk of sexual minority individuals by contrasting the minority stress model with suicide models. Archives of Sexual Behavior, 43(8), 1559-1570. doi:10.1007/s10508-014-0268-4.

Qin, P., Agerbo, E. \& Mortensen, P. B. (2003). Suicide risk in relation to socioeconomic, demographic, psychiatric, and familial factors: A national register-based study of all suicides in Denmark, 1981-1997. American Journal of Psychiatry, 160(4), 765-772. doi:10.1176/appi.ajp.160.4.765.

Riggs, D. W. \& Treharne, G. J. (2016). Decompensation: A novel approach to accounting for stress arising from the effects of ideology and social norms. Journal of Homosexuality. http://dx.doi.org/10.1080/00918369.2016.1194116

*Rood, B. A., Puckett, J. A., Pantalone, D. W. \& Bradford, J. B. (2015). Predictors of suicidal ideation in a statewide sample of transgender individuals. LGBT Health, 2(3), 270-275. doi:10.1089/lgbt.2013.0048.

*Skagerberg, E., Parkinson, R. \& Carmichael, P. (2013). Self-harming thoughts and behaviors in a group of children and adolescents with gender dysphoria. International Journal of Transgenderism, 14(2), 86-92. doi:10.1080/15532739.2013.817321.

*Tebbe, E. A. \& Moradi, B. (2016). Suicide risk in trans populations: An application of minority stress theory. Journal of Counseling Psychology, 63(5), 520-533. doi: $10.1037 /$ cou0000152. 
*Terada, S., Matsumoto, Y., Sato, T., Okabe, N., Kishimoto, Y. \& Uchitomi, Y. (2011). Suicidal ideation among patients with gender identity disorder. Psychiatry Research, 190, 159-162. Retrieved from Science Direct, July 2015.

Testa, R., Habarth, J., Peta, J., Balsam, K. \& Bockting, W. (2015). Development of the Gender Minority Stress and Resilience measure. Psychology of Sexual Orientation and Gender Diversity, 2(1), 65-77. doi:10.1037/sgd0000081.

Testa, R. J., Jimenez, C. L. \& Rankin, S. (2014). Risk and resilience during transgender identity development: The effects of awareness and engagement with other transgender people on affect. Journal of Gay \& Lesbian Mental Health, 18,(1), 31-46. doi:10.1080/19359705.2013.805177.

*Testa, R. J., Sciacca, L. M., Wang, F., Hendricks, M. L., Goldblum, P., Bradford, J. \& Bongar, B. (2012). Effects of violence on transgender people. Professional Psychology: Research \& Practice, 43(5), 452-459. doi:10.1037/a0029604.

Vandenbroucke, J. P., von Elm, E., Altman, D. G., Gotzsche, P. C., Mulrow, C. D., Pocock, S. J., Poole, C., Schlesselman, J. J. \& Egger, M. (2007). Strengthening the reporting of observational studies in epidemiology (STROBE): Explanation and elaboration. Epidemiology, 18(6), 805-835. doi:10.1097/EDE.0b013e3181577511.

*Wilson, E. C., Chen, Y-H., Arayasirikul, S., Wenzel, C. \& Raymond, H. F. (2014). Connecting the dots: Examining transgender women's utilization of transitionrelated medical care and associations with mental health, substance use, and HIV. Journal of Urban Health: Bulletin Of The New York Academy Of Medicine, 92(1), 182-192. doi:10.1007/s11524-014-9921-4. 
Wilson, E. R. (2012). Assessment, diagnosis and treatment planning from the ecological perspective. In E. P. Cook (Ed.), Understanding people in context: The ecological perspective in counselling (pp. 179-206). Alexandria, VA: American Counseling Association.

*Xavier, J. M., Bobbin, M., Singer, B. \& Budd, E. (2005). A needs assessment of transgendered people of color living in Washington, DC. International Journal of Transgenderism, 8(2-3), 31-47. doi:10.1300/J485v08n02_04. 
Table 1

Articles included in the systematic review

\begin{tabular}{|c|c|c|c|c|}
\hline Paper & Author(s) & Location & Aim & Sample size and composition \\
\hline 1 & $\begin{array}{l}\text { Bauer, Scheim, } \\
\text { Pyne, Travers \& } \\
\text { Hammond (2015) }\end{array}$ & Canada & $\begin{array}{c}\text { Identify intervenable } \\
\text { social factors associated } \\
\text { with a reduction in suicide } \\
\text { risk. }\end{array}$ & $\begin{array}{c}\mathrm{N}=380 \\
\text { Trans women }(47.4 \%) \text { and trans } \\
\text { men }(52.6 \%)\end{array}$ \\
\hline 2 & $\begin{array}{l}\text { Clements-Nolle, } \\
\text { Marx \& Katz } \\
\text { (2006) }\end{array}$ & USA & $\begin{array}{l}\text { Explore whether } \\
\text { victimization and } \\
\text { discrimination were } \\
\text { independently associated } \\
\text { with attempted suicide. }\end{array}$ & $\begin{array}{c}\mathrm{N}=515 \\
\text { MTFs }(\mathrm{n}=392) \text { and FTMs } \\
(\mathrm{n}=123) .\end{array}$ \\
\hline 3 & $\begin{array}{l}\text { Colizzi, Costa \& } \\
\text { Todarello (2015) }\end{array}$ & Italy & $\begin{array}{l}\text { Explore prevalence of } \\
\text { dissociative disorders and } \\
\text { symptoms before and } \\
\text { after hormone therapy. }\end{array}$ & $\begin{array}{c}\mathrm{N}=118 \\
\text { MTFs }(\mathrm{n}=82) \text { and FTMs }(\mathrm{n}=36) \text {. }\end{array}$ \\
\hline 4 & $\begin{array}{l}\text { Effrig, Bieschke \& } \\
\quad \text { Locke (2011) }\end{array}$ & USA & $\begin{array}{c}\text { Explore rates of } \\
\text { harassment and } \\
\text { discrimination, and } \\
\text { mental health of college } \\
\text { students, comparing those } \\
\text { seeking treatment and } \\
\text { those not. }\end{array}$ & $\begin{array}{l}\text { Sample } 1 \text { (not in or seeking } \\
\text { counselling services): } \mathrm{N}=21686 \text { : } \\
\text { trans people (gender unknown) } \\
\text { and others ( } \mathrm{n}=68) \text {; cis women } \\
(\mathrm{n}=13244) \text {; cis men }(\mathrm{n}=7191) \text {. } \\
\text { Sample } 2 \text { (clinical sample seeking } \\
\text { or receiving counselling services): } \\
\mathrm{N}=27616 \text { : trans people (gender } \\
\text { unknown) }(\mathrm{n}=40) \text {; cis women } \\
(\mathrm{n}=16615) \text { cis men }(\mathrm{n}=9141) .\end{array}$ \\
\hline 5 & $\begin{array}{l}\text { Goldblum, Testa, } \\
\text { Pflum, Hendricks, } \\
\text { Bradford \& } \\
\text { Bongar (2012) }\end{array}$ & USA & $\begin{array}{l}\text { Explore relationship } \\
\text { between gender based } \\
\text { victimisation during } \\
\text { school, and attempted } \\
\text { suicide. }\end{array}$ & $\begin{array}{l}\mathrm{N}=290 \\
\text { Trans women ( } \mathrm{n}=147), 33 \text { with no } \\
\text { plans to transition "full time". } \\
\text { Trans men (n=81), } 29 \text { with no } \\
\text { transition plans. }\end{array}$ \\
\hline 6 & $\begin{array}{c}\text { Grossman \& } \\
\text { D'Augelli (2007) }\end{array}$ & USA & $\begin{array}{l}\text { Explore whether 'life- } \\
\text { threatening behaviours' } \\
\text { related to parental } \\
\text { reactions to participant's } \\
\text { gender, and feelings about } \\
\text { their bodies. }\end{array}$ & $\begin{array}{c}\mathrm{N}=55 \\
\text { Young people: } \operatorname{MTF}(\mathrm{n}=31) \text { and } \\
\text { FTM }(\mathrm{n}=24)\end{array}$ \\
\hline
\end{tabular}




\begin{tabular}{|c|c|c|c|c|}
\hline 7 & $\begin{array}{c}\text { Grossman, Park \& } \\
\text { Russell (2016) }\end{array}$ & USA & $\begin{array}{l}\text { Explore suicidal ideation } \\
\text { and attempt in relation to } \\
\text { perceived } \\
\text { burdensomeness and } \\
\text { thwarted belongingness. }\end{array}$ & $\begin{array}{c}\mathrm{N}=129 \\
\text { Young people: MTF }(\mathrm{n}=44), \text { FTM } \\
(\mathrm{N}=40, \text { MTDG }(\mathrm{n}=14), \text { and FTDG } \\
(\mathrm{n}=31)\end{array}$ \\
\hline 8 & $\begin{array}{l}\text { Heylens, Elaut, } \\
\text { Kreukels, Paap, } \\
\text { Cerwenka, } \\
\text { Richter-Appelet, } \\
\text { Cohen-Kettenis, } \\
\text { Haraldsen \& De } \\
\text { Cuypere (2014) }\end{array}$ & $\begin{array}{l}\text { The } \\
\text { Netherlan } \\
\text { ds, } \\
\text { Belgium, } \\
\text { Germany, } \\
\text { Norway }\end{array}$ & $\begin{array}{l}\text { Obtain rates of psychiatric } \\
\text { diagnoses in people } \\
\text { seeking gender } \\
\text { reassignment, who also } \\
\text { had been diagnosed with } \\
\text { gender identity disorder. }\end{array}$ & $\begin{array}{c}\mathrm{N}=305 \\
\text { MTFs }(\mathrm{n}=182) \text { and FTMs }(\mathrm{n}=123) \\
\text { attending a gender clinic } \\
\text { diagnosed with gender identity } \\
\text { disorder. }\end{array}$ \\
\hline 9 & $\begin{array}{c}\text { Heylens, } \\
\text { Verroken, De } \\
\text { Cock, T'Sjoen \& } \\
\text { De Cuypere } \\
\text { (2014) }\end{array}$ & $\begin{array}{l}\text { Ghent, } \\
\text { Belgium }\end{array}$ & $\begin{array}{l}\text { Explore the psychological } \\
\text { impact of different stages } \\
\text { of medical gender } \\
\text { reassignment } \\
\text { interventions. }\end{array}$ & $\begin{array}{l}\mathrm{N}=57 \\
\text { MTFs }(\mathrm{n}=46) \text { and FTMs }(\mathrm{n}=11) \\
\text { undergoing gender confirmation } \\
\text { surgery within a gender clinic. }\end{array}$ \\
\hline 10 & $\begin{array}{l}\text { Hoshiai, } \\
\text { Matsumoto, Sato, } \\
\text { Ohnishi, Okabe, } \\
\text { Kishimoto, Terada } \\
\text { \& Kuroda (2010) }\end{array}$ & Japan & $\begin{array}{l}\text { Investigate psychiatric } \\
\text { comorbidity and life } \\
\text { events in people attending } \\
\text { the gender clinic. }\end{array}$ & $\begin{array}{l}\mathrm{N}=579 . \\
\text { Male-to-female type }(\mathrm{n}=230) \text { and } \\
\text { female-to-male type }(\mathrm{n}=349) \\
\text { attending a gender clinic. }\end{array}$ \\
\hline 11 & $\begin{array}{l}\text { House, Van Horn, } \\
\text { Coppeans, } \\
\text { Stepleman (2011) }\end{array}$ & USA & $\begin{array}{l}\text { Explore whether } \\
\text { discrimination and } \\
\text { interpersonal trauma } \\
\text { relates to suicidal } \\
\text { behaviours and self-injury } \\
\text { in LGBT people. }\end{array}$ & $\begin{array}{l}\mathrm{N}=1126 \text { LGBT people. Trans } \\
\text { people }(\mathrm{n}=164) \text { : } \\
\text { women/feminine }(\mathrm{n}=135) \text { and } \\
\text { men/masculine people }(\mathrm{n}=29) \text {. }\end{array}$ \\
\hline 12 & $\begin{array}{c}\text { Kenagy \& } \\
\text { Bostwick (2005) }\end{array}$ & USA & $\begin{array}{l}\text { Discussion of trans } \\
\text { community needs } \\
\text { assessment findings. }\end{array}$ & $\begin{array}{c}\mathrm{N}=138 \text {. } \\
\text { MTFs }(\mathrm{n}=78) \text { and FTMs }(\mathrm{n}=33) \text {. }\end{array}$ \\
\hline 13 & $\begin{array}{l}\text { Lehavot, Simpson } \\
\text { \& Shipherd (2016) }\end{array}$ & USA & $\begin{array}{l}\text { Explore correlates of } \\
\text { suicidal ideation and } \\
\text { suicide risk in transgender } \\
\text { veterans. }\end{array}$ & $\begin{array}{c}\mathrm{N}=212 \\
\text { Trans women }(\mathrm{n}=186) \text { and trans } \\
\text { men }(\mathrm{n}=26)\end{array}$ \\
\hline 14 & $\begin{array}{l}\text { Lobato, Koff, } \\
\text { Schestatsky, de } \\
\text { Vasconcellos } \\
\text { Chaves, Petry, } \\
\text { Crestana, Amaral, }\end{array}$ & Brazil & $\begin{array}{l}\text { Discuss the psychosocial } \\
\text { characteristics of people } \\
\text { using a clinic in Brazil. }\end{array}$ & $\begin{array}{c}\mathrm{N}=138 \text {. } \\
\text { MTFs }(\mathrm{n}=122) \text { and FTMs }(\mathrm{n}=16) \text {. }\end{array}$ \\
\hline
\end{tabular}




\begin{tabular}{|c|c|c|c|c|}
\hline & $\begin{array}{c}\text { de Quandros } \\
\text { Onofrio, Salvador, } \\
\text { Silviera \& } \\
\text { Henriques (2007) }\end{array}$ & & & \\
\hline 15 & $\begin{array}{c}\text { Maguen \& } \\
\text { Shipherd (2010) }\end{array}$ & USA & $\begin{array}{l}\text { Report the frequency and } \\
\text { predictive factors related } \\
\text { to suicide in trans groups. }\end{array}$ & $\begin{array}{l}\mathrm{N}=153 \text {. } \\
125 \text { people assigned male at birth } \\
\text { (6\% of whom had a male gender } \\
\text { identity, } 45 \% \text { with a somewhat or } \\
\text { entirely female identity), and } 28 \\
\text { people assigned female at birth } \\
\text { (7\% of whom had a female gender } \\
\text { identity, } 83 \% \text { with a somewhat or } \\
\text { entirely male identity). }\end{array}$ \\
\hline 16 & $\begin{array}{l}\text { Marshall, Socías, } \\
\text { Kerr, Salazar, } \\
\text { Sued \& Arístegui } \\
\text { (2015) }\end{array}$ & Argentina & $\begin{array}{l}\text { To examine the } \\
\text { prevalence and correlates } \\
\text { of suicide attempts in } \\
\text { Argentinian trans people. }\end{array}$ & $\begin{array}{c}\mathrm{N}=482 . \\
\text { Trans women }(\mathrm{n}=438) \text { and trans } \\
\text { men }(\mathrm{n}=44) .\end{array}$ \\
\hline 17 & Mathy (2003) & USA & $\begin{array}{l}\text { Explored whether trans } \\
\text { people were at an } \\
\text { increased risk of suicide, } \\
\text { with LGB trans people } \\
\text { being at an increased risk } \\
\text { to heterosexual trans } \\
\text { people. Also whether } \\
\text { suicidal trans people } \\
\text { would be more likely to } \\
\text { use support services and } \\
\text { have compulsivity issues } \\
\text { than non-suicidal trans } \\
\text { people }\end{array}$ & $\begin{array}{l}\mathrm{N}=2991 \\
\text { Whole sample separated and } \\
\text { reduced to comparison groups: } \\
\text { heterosexual trans people ( } \mathrm{n}=29) \text {, } \\
\text { non-heterosexual trans people ( } \mathrm{n}- \\
\text { 44), heterosexual cis women } \\
(\mathrm{n}=1083) \text {, lesbian cis women } \\
(\mathrm{n}=256) \text {, heterosexual cis men } \\
(\mathrm{n}=1077) \text {, gay cis men }(\mathrm{n}=356), \\
\text { psychosocially matched cis } \\
\text { women }(\mathrm{n}=73) \text {, psychosocially } \\
\text { matched cis men }(\mathrm{n}=73) .\end{array}$ \\
\hline 18 & $\begin{array}{l}\text { Meier, Fitzgerald, } \\
\text { Pardo, Babcock } \\
\text { (2011) }\end{array}$ & $\begin{array}{l}\text { Mainly } \\
\text { USA }\end{array}$ & $\begin{array}{l}\text { Provide evidence } \\
\text { concerning the impact of } \\
\text { testosterone on trans } \\
\text { men's psychological state }\end{array}$ & $\begin{array}{l}\mathrm{N}=369 \text {. } \\
\text { FTM transsexual only sample. }\end{array}$ \\
\hline 19 & $\begin{array}{l}\text { Miller \& Grollman } \\
\qquad(2015)\end{array}$ & USA & $\begin{array}{l}\text { Explored whether } \\
\text { perceived gender } \\
\text { nonconformity was } \\
\text { related to major and } \\
\text { everyday transphobic } \\
\text { discrimination, and } \\
\text { whether transphobic }\end{array}$ & $\begin{array}{c}\mathrm{N}=4115 . \\
\text { Trans men }(\mathrm{n}=1601) \text { and trans } \\
\text { women }(\mathrm{n}=2514) .\end{array}$ \\
\hline
\end{tabular}




\begin{tabular}{|c|c|c|c|c|}
\hline & & & $\begin{array}{l}\text { discrimination related to } \\
\text { attempted suicide. Also } \\
\text { whether transphobic } \\
\text { discrimination mediated } \\
\text { any relationship between } \\
\text { nonconformity and } \\
\text { attempted suicide. }\end{array}$ & \\
\hline 20 & $\begin{array}{l}\text { Nemoto, Bodeker } \\
\& \text { Iwamoto (2011) }\end{array}$ & USA & $\begin{array}{l}\text { Describe the impact of } \\
\text { violence, transphobic } \\
\text { events and social support } \\
\text { in trans women with a } \\
\text { history of sex work, in } \\
\text { relation to their } \\
\text { ethnic/racial identity }\end{array}$ & $\begin{array}{c}\mathrm{N}=573 \\
\text { Trans women with a history of } \\
\text { sex work who identified as either } \\
\text { African American }(n=253), \\
\text { Asians/Pacific Islanders (APIs; } \\
n=110), \text { Latina }(n=110) \text { or White } \\
(n=118) .\end{array}$ \\
\hline 21 & $\begin{array}{l}\text { Nuttbrock, } \\
\text { Hwnhng, } \\
\text { Bockting, } \\
\text { Rosenblum, } \\
\text { Mason \& Becker } \\
\text { (2010) }\end{array}$ & USA & $\begin{array}{l}\text { Establish the impact of } \\
\text { gender-related abuse } \\
\text { across the lifetime. In } \\
\text { particular on depression } \\
\text { and suicide }\end{array}$ & $\begin{array}{l}\mathrm{N}=571 \text {. } \\
\text { Male-to-female transgender } \\
\text { people only sample. }\end{array}$ \\
\hline 22 & $\begin{array}{c}\text { Operario \& } \\
\text { Nemoto (2005) }\end{array}$ & USA & $\begin{array}{c}\text { Estimate HIV risk } \\
\text { behaviours in API trans } \\
\text { women }\end{array}$ & $\begin{array}{c}\mathrm{N}=110 \\
\text { Asian/Pacific Island MTF } \\
\text { transgenders. }\end{array}$ \\
\hline 23 & $\begin{array}{l}\text { Perez-Brumer, } \\
\text { Hatzenbuehler, } \\
\text { Oldenburg \& } \\
\text { Bockting (2015) }\end{array}$ & USA & $\begin{array}{l}\text { Explore relationship } \\
\text { between both individual } \\
\text { and structural stigma, and } \\
\text { attempted suicide in a } \\
\text { mixed trans group }\end{array}$ & $\begin{array}{l}\mathrm{N}=1229 . \\
\text { Sample separated and coded as } \\
\text { male-to-female }(\mathrm{n}=697) \text { or } \\
\text { female-to-male }(\mathrm{n}=532)\end{array}$ \\
\hline 24 & $\begin{array}{l}\text { Rood, Puckett, } \\
\text { Pantalone \& } \\
\text { Bradford (2015) }\end{array}$ & USA & $\begin{array}{l}\text { Explore whether } \\
\text { transition, violence and } \\
\text { discrimination relate to } \\
\text { suicidal ideation, and } \\
\text { whether transition and } \\
\text { discrimination interact }\end{array}$ & $\begin{array}{c}\mathrm{N}=350 . \text { Transgender } \\
\text { women/MTF }(\mathrm{n}=229) \text { and } \\
\text { transgender men/FTM } \\
(\mathrm{n}=121) .\end{array}$ \\
\hline 25 & $\begin{array}{c}\text { Skagerberg, } \\
\text { Parkinson \& } \\
\text { Carmichael (2013) }\end{array}$ & UK & $\begin{array}{l}\text { Describe suicidal } \\
\text { behaviours and self-harm } \\
\text { in young people prior to } \\
\text { attending a gender clinic }\end{array}$ & $\begin{array}{l}\mathrm{N}=125 \text {. } \\
\text { Natal males }(\mathrm{n}=68) \text {, and natal } \\
\text { females }(\mathrm{n}=57) \text {. }\end{array}$ \\
\hline 26 & $\begin{array}{l}\text { Tebbe \& Moradi } \\
\text { (2016) }\end{array}$ & USA & $\begin{array}{l}\text { Tested the relation of } \\
\text { minority stress and } \\
\text { internalised transphobia }\end{array}$ & $\begin{array}{c}\mathrm{N}=335 \\
\text { Transmen }(\mathrm{n}=90) \text {, transwomen }\end{array}$ \\
\hline
\end{tabular}




\begin{tabular}{|c|c|c|c|c|}
\hline & & & $\begin{array}{l}\text { with depression and } \\
\text { suicide risk }\end{array}$ & $(\mathrm{n}=110)$, nonbinary $(\mathrm{n}=128)$ \\
\hline 27 & $\begin{array}{c}\text { Terada, } \\
\text { Matsumoto, Sato, } \\
\text { Okabe, Kishimoto } \\
\text { \& Uchitomi } \\
\text { (2011) }\end{array}$ & Japan & $\begin{array}{l}\text { Describe risk factors for } \\
\text { suicidal ideation and self- } \\
\text { harm in people attending } \\
\text { a gender clinic }\end{array}$ & $\begin{array}{c}\mathrm{N}=500 . \\
\text { MTF type }(\mathrm{n}=189) \text { and FTM type } \\
(\mathrm{n}=311) .\end{array}$ \\
\hline 28 & $\begin{array}{l}\text { Testa, Sciacca, } \\
\text { Wang, Hendricks, } \\
\text { Goldblum, } \\
\text { Bradford \& } \\
\text { Bongar (2012) }\end{array}$ & USA & $\begin{array}{l}\text { Explore whether physical } \\
\text { violence and sexual } \\
\text { assault relate to suicide } \\
\text { and substance misuse }\end{array}$ & $\begin{array}{l}\mathrm{N}=271 . \\
\text { Trans women }(\mathrm{n}=179), \text { trans men } \\
(\mathrm{n}=92) .\end{array}$ \\
\hline 29 & $\begin{array}{l}\text { Wilson, Chen, } \\
\text { Arayasirikul, } \\
\text { Wenzel \& } \\
\text { Raymond (2014) }\end{array}$ & USA & $\begin{array}{l}\text { Explore impact on mental } \\
\text { health of trans women, of } \\
\text { using different physical } \\
\text { transition-related } \\
\text { interventions }\end{array}$ & $\begin{array}{c}\mathrm{N}=314 \\
\text { Transwomen only sample. }\end{array}$ \\
\hline 30 & $\begin{array}{l}\text { Xavier, Bobbin, } \\
\text { Singer \& Budd } \\
\quad(2005)\end{array}$ & USA & $\begin{array}{l}\text { Discussion of trans } \\
\text { community needs } \\
\text { assessment findings }\end{array}$ & $\begin{array}{l}\mathrm{N}=248 . \\
\text { Natal males/MTFs }(\mathrm{n}=188) \text { and } \\
\text { natal females/FTMs }(\mathrm{n}=60) .\end{array}$ \\
\hline
\end{tabular}




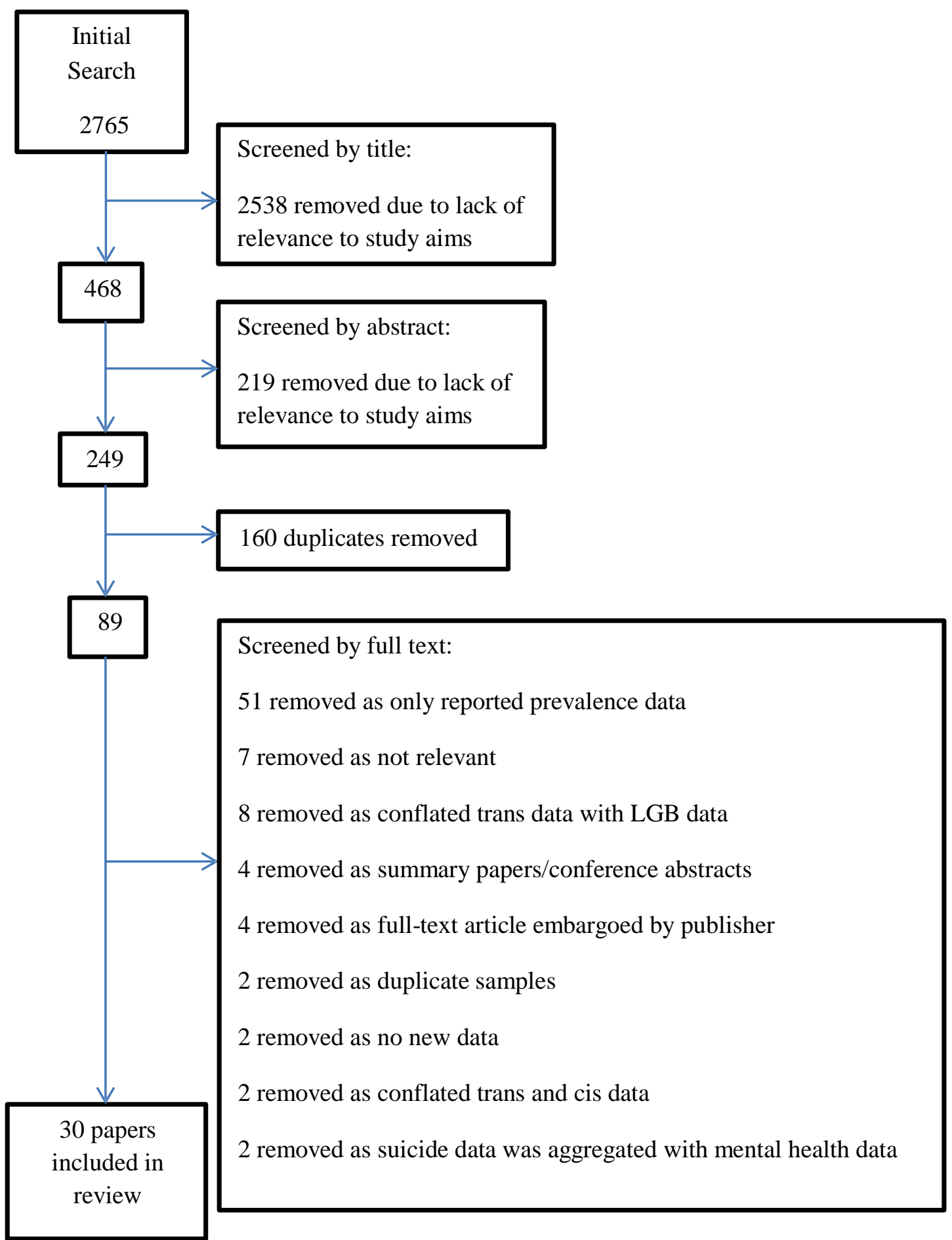

Figure 1. Flow diagram of paper selection 